\title{
Near IR Refractive Index for GaInN Heavily Doped with Silicon
}

\author{
G. Cywiński ${ }^{a}$, R. Kudrawiec ${ }^{b}$,W. Rzodkiewicz ${ }^{c}$, M. KrYŚKO $^{a}$, E. Litwin-Staszewska $^{a}$, \\ J. Misiewicz ${ }^{b}$ AND C. SkiERBiszewSKI ${ }^{a}$ \\ ${ }^{a}$ Institute of High Pressure Physics, Polish Academy of Sciences, Sokołowska 29/37, 01-142 Warsaw, Poland \\ ${ }^{b}$ Institute of Physics, Wrocław University of Technology, Wybrzeże Wyspiańskiego 27, 50-370 Wrocław, Poland \\ ${ }^{c}$ Institute of Electron Technology, al. Lotników 32/46, 02-668 Warsaw, Poland
}

\begin{abstract}
The authors report on growth and results of infrared measurements of GaInN heavily doped with silicon. The lattice matched to GaN epitaxial layer of $\mathrm{Ga}_{0.998} \mathrm{In}_{0.002} \mathrm{~N}$ :Si has been grown in plasma assisted molecular beam epitaxy in the metal rich conditions. The room temperature Hall concentration and mobility of electrons are $2 \times 10^{20} \mathrm{~cm}^{-3}$ and $67 \mathrm{~cm}^{2} /(\mathrm{Vs})$, respectively. The refractive index has been determined by variable angle spectroscopic ellipsometry. The refractive index exhibited a significant reduction of its value (from 2.25 to 2 at $1.55 \mu \mathrm{m})$ at near IR range where are the main interests of potential applications for nitride based intersubband devices. Reported here values of refractive indices at 1.55 and $1.3 \mu \mathrm{m}$ are appropriate for fabrication of cladding layers with the required contrast to $\mathrm{GaN}$ for intersubband devices. The observed drop of refractive index is attributed to the carrier-induced plasma edge effect, which has been directly observed in reflectance spectrum.
\end{abstract}

PACS numbers: 61.72.uj, 78.66.Fd, 81.15.Hi, 68.55.-a, 78.20.-e

\section{Introduction}

The wide-band gap III-nitrides attract a lot of attention because of their application in fabrication of various optoelectronic devices. One of the main streams of worldwide research focuses on the development of GaN-based light emitters and laser diodes emitting in visible and ultraviolet spectral range [1-3]. Moreover, III-nitrides can be also used in the infrared (IR) spectral range in intersubband (IS) devices which use only one type of carriers (usually electrons).

Currently, III-nitride IS devices are under an intense investigation towards their application in ultrafast telecommunication networks [4-14]. So far, the near-infrared $(1.3-1.55 \mu \mathrm{m})$ IS transitions have been successfully realized in III-nitrides. In addition, it has been demonstrated that III-nitride IS switches are very fast due to the strong electron-phonon interaction, e.g. a $10 \mathrm{~dB}$ switching with a gate width as short as $230 \mathrm{fs}$ has been demonstrated in Ref. [11]. It is worth noting that much faster $(\approx 1 \mathrm{Tbit} / \mathrm{s})$ IS devices are expected in this material system from the theoretical point of view. This speed is much higher than physical limits of the currently used devices. In spite of the intensive progress in this field for the last decade, the present III-nitride IS devices are still under development and they are rather far from matching the requirements for commercialization. One of the main problems is their quality since the lattice mismatch between AlN and GaN, which are commonly used for these devices, causes cracking and a formation of many structural defects. This problem is very serious in real optoelectronic devices operating in the IR spectral range where thick layers with a large contrast of refractive indices are required for the fabrication of appropriate waveguides.

An alternative way to produce IS devices could be the application of GaN lattice matched layers where the contrast in the refractive index appears due to the plasma effect $[15,16]$. This idea is intensely explored in III-V mid- and far-IR quantum cascade lasers but in the case of III-nitride IR devices this phenomenon has not been explored experimentally yet.

In general, it is expected that the plasma edge effect for GaN-based materials appears at longer wavelengths than for GaAs- or GaSb-based materials because of much higher electron effective mass. As a result the Si-doping in GaN-based structures was not investigated in the context of its application in optical waveguides operating at telecommunication wavelengths (i.e., 1.3 and $1.55 \mu \mathrm{m}$ ) and the Si-induced contrast in the refractive index in this material system at these wavelengths is unknown from the experimental point of view.

In this paper we have applied IR measurements to investigate the plasma effect in Si-doped GaInN layer. In the present work, the refractive index at near IR range has been measured by spectroscopic ellipsometry. The found low value of the refractive index has been discussed in the context of its application in IS devices operating at telecommunication wavelengths. 


\section{Experimental}

The $\mathrm{In}_{0.002} \mathrm{Ga}_{0.998} \mathrm{~N}$ :Si layer was grown by plasma assisted molecular beam epitaxy on GaN undoped template obtained by metal organic vapor phase epitaxy (MOVPE) on a (0001) sapphire substrate. The growth has begun with a thin startup layer $\mathrm{In}_{0.05} \mathrm{Ga}_{0.95} \mathrm{~N}$, then the main $\mathrm{In}_{0.002} \mathrm{Ga}_{0.998} \mathrm{~N}$ :Si layer has been deposited. We have used indium as the surfactant and a low temperature growth regime. The epitaxial growth has been carried out in a metal rich condition on the boundary of the metal droplet formation. The desorption of indium has been used for the determination of proper substrate temperature using the method described in Ref. [17]. To determine the beginning of droplets formation during the growth we have used the scattered light technique similar to shown in papers [18]. To collect only a part of the scattered signal which comes from the substrate surface we have used the $325 \mathrm{~nm}$ laser light and sets of filters. After the sudden increase in scattered light signal, caused by crossing through droplet formation, we have increased the substrate temperature by a few degrees. This increase of the growth temperature stopped the metal accumulation process on the initial stage, where the droplet formation is still revisable.

\section{Results}

The X-ray diffraction measurements, including the reciprocal space mapping (see Fig. 1), confirmed the high structural quality of the layer and a small indium content, i.e., $0.2 \%$. Distortion of the GaInN lattice parameter due to the free carriers [19] has been taken into account for the determination of indium content. The electron concentration has been determined using the room temperature Van der Pauw method. The Hall concentration and mobility of electrons have been measured to be $2 \times 10^{20} \mathrm{~cm}^{-3}$ and $67 \mathrm{~cm}^{2} /(\mathrm{V} \mathrm{s})$, respectively. The ellipsometry setup was used to measure the optical spectra at the near IR range for the layered and reference sample which was the GaN/sapphire MOVPE template.

The refractive index for GaInN:Si and GaN layers has been determined from ellipsometry measurements which were performed up to $1.7 \mu \mathrm{m}$. Spectroscopic ellipsometry measurements were performed at room temperature with a Variable Angle Spectroscopic Ellipsometer of J.A. Woollam. The applied instrument works in configuration of a rotating analyzer ellipsometer. Precise measurements were carried out at the angles $30^{\circ}-84^{\circ}$ (with a $0.5^{\circ}$ step) at the wavelengths $700-1700 \mathrm{~nm}$ with a $10 \mathrm{~nm}$ step. It has been found that for GaN layer the refractive index is in a good agreement with the literature [20]. Results obtained from these measurements are plotted in the wavelength scale in Fig. 2. Above the wavelength of $1 \mu \mathrm{m}$ the refractive index for the GaInN:Si layer has been found to be much smaller than for the reference sample ( 2 instead of 2.25 at $1.55 \mu \mathrm{m}$ ). This observation is very consistent with our expectations. The differences in refractive indices between GaInN:Si and GaN have been

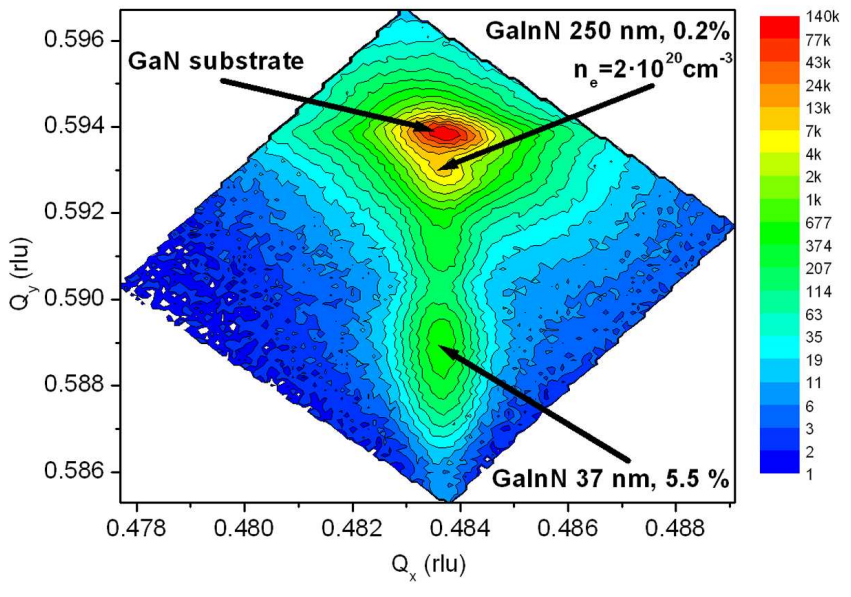

Fig. 1. The reciprocal space mapping of epitaxial structure.

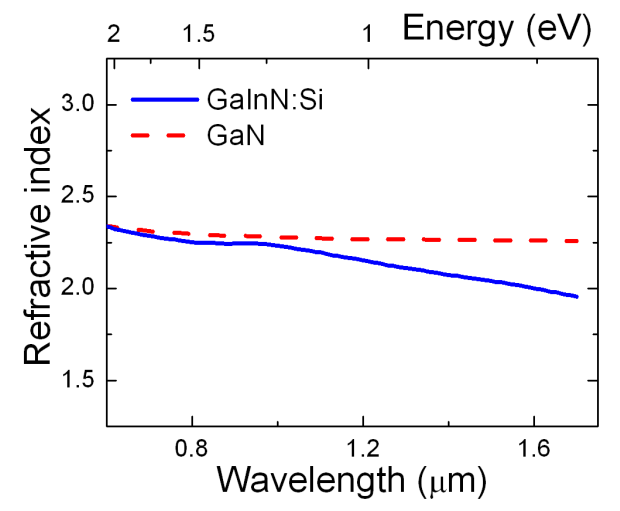

Fig. 2. Refractive index of GaInN:Si and GaN layers determined from ellipsometry measurements.

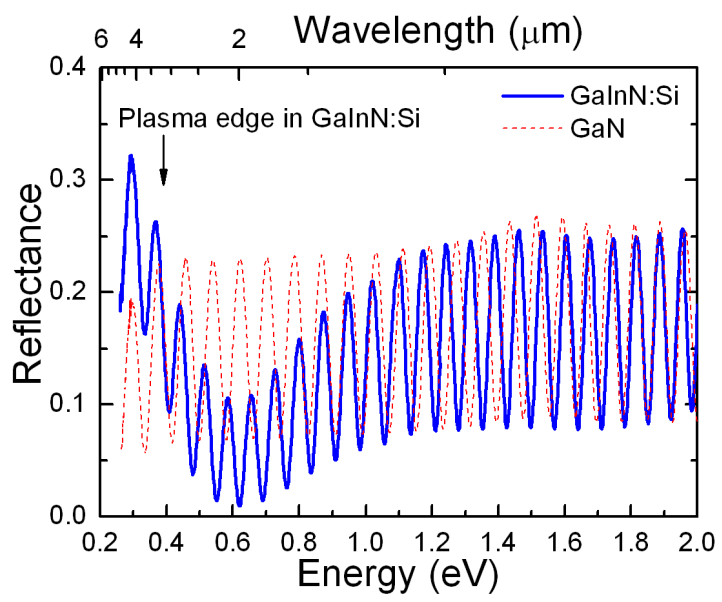

Fig. 3. Room temperature reflectance spectra for GaInN:Si and GaN layers. 
found to be $9.6 \%$ and $8.4 \%$ for 1.55 and $1.3 \mu \mathrm{m}$, respectively. The change in the refractive index for GaInN:Si in the infrared spectral range is attributed to the plasma edge effect which is directly observed in reflectance spectrum, see Fig. 3.

In conclusion, the spectroscopic ellipsometry has been used to measure the refractive index for heavily Si-doped GaInN layer. The observed decrease of the refractive index due to the plasma edge effect has been clearly observed at the telecommunication wavelengths. This effect can be used to grow GaN-based waveguides operating at $1.55 \mu \mathrm{m}$.

\section{Acknowledgments}

This work was partially supported by the Polish Ministry of Science and Higher Education as scientific projects no. N507 01132/0500 and the European Union within European Regional Development Fund, through grant Innovative Economy (POIG.01.01.02-00-008/08). In addition, R.K. acknowledges for financial support from the Foundation for Polish Science.

\section{References}

[1] S. Nakamura, G. Fasol, The Blue Laser Diode, Springer, Berlin 1997.

[2] S. Nakamura, M. Senoh, S. Nagahama, N. Iwasa, T. Yamada, T. Matsushita, H. Kiyoku, Y. Sugimoto, T. Kozaki, H. Umemoto, M. Sano, K. Chocho, Appl. Phys. Lett. 72, 2014 (1998).

[3] C. Skierbiszewski, Z.R. Wasilewski, M. Siekacz, A. Feduniewicz, P. Perlin, P. Wiśniewski, J. Borysiuk, I. Grzegory, M. Leszczyński, T. Suski, S. Porowski, Appl. Phys. Lett. 86, 011114 (2005).

[4] N. Suzuki, N. Iizuka, Jpn. J. Appl. Phys. 36, L1006 (1997).

[5] C. Gmachl, H.M. Ng, S.-N.G. Chu, A.Y. Cho, Appl. Phys. Lett. 77, 3722 (2000).

[6] K. Kishino, A. Kikuchi, H. Kanazawa, T. Tachiana, Appl. Phys. Lett. 81, 1234 (2002).
[7] N. Iizuka, K. Kaneko, N. Suzuki, Appl. Phys. Lett. 81, 1803 (2002).

[8] K. Kishino, A. Kikuchi, H. Kanazawa, T. Tachibana, Appl. Phys. Lett. 81, 1234 (2002).

[9] I. Waki, C. Kumtornkittikul, Y. Shimogaki, Y. Nakano, Appl. Phys. Lett. 82, 4465 (2003).

[10] S. Nicolay, J.-F. Carlin, E. Feltin, R. Butte, M. Mosca, N. Grandjean, M. Ilegems, M. Tchernycheva, L. Nevou, F.H. Julien, Appl. Phys. Lett. 87, 111106 (2005).

[11] N. Iizuka, K. Kaneko, N. Suzuki, Opt. Exp. 13, 3835 (2005).

[12] G. Cywiński, C. Skierbiszewski, A. Feduniewicz-Żmuda, M. Siekacz, L. Nevou, L. Doyennette, M. Tchernycheva, F.H. Julien, P. Prystawko, M. Kryśko, S. Grzanka, I. Grzegory, A. Presz, J.Z. Domagała, J. Smalc, M. Albrecht, T. Remmele, S. Porowski, J. Vac. Sci. Technol. B 24, 1505 (2006).

[13] M. Motyka, R. Kudrawiec, G. Cywiński, M. Siekacz, C. Skierbiszewski, J. Misiewicz, Appl. Phys. Lett. 89, 251908 (2006).

[14] M. Tchernycheva, L. Nevou, L. Doyennette, F.H. Julien, E. Warde, F. Guillot, E. Monroy, E. Bellet-Amalric, T. Remmele, M. Albrecht, Phys. Rev. B 73, 125347 (2006).

[15] P. Holmström, Physica E 7, 40 (2000).

[16] P. Holmström, IEEE J. Quantum Electron. 42, 810 (2006).

[17] M. Siekacz, M.Ł. Szańkowska, A. Feduniewicz-Żmuda, J. Smalc-Koziorowska, G. Cywiński, S. Grzanka, Z.R. Wasilewski, I. Grzegory, B. Łucznik, S. Porowski, C. Skierbiszewski, Phys. Status Solidi C 6, 917 (2009).

[18] T. Pinnington, C. Lavoie, T. Tiedje, B. Haveman, E. Nodwell, Phys. Rev. Lett. 79, 1698 (1997); T. Pinnington, Y. Levy, J.A. MacKenzie, T. Tiedje, Phys. Rev. B 60, 15901 (1999).

[19] M. Kryśko, M. Sarzyński, J. Domagała, I. Grzegory, B. Łucznik, G. Kamler, S. Porowski, M. Leszczyński, J. Alloys Comp. 401, 261 (2005).

[20] N. Watanabe, T. Kimoto, Jun Suda, J. Appl. Phys. 104, 106101 (2008); M.J. Bergmann, U. Ozgur, H.C. Casey, Jr., H.O. Everitt, J.F. Muth, Appl. Phys. Lett. 75, 67 (1999); G. Yu, G. Wang, H. Ishikawa, M. Umeno, T. Soga, T. Egawa, J. Watanabe, T. Jimbo, Appl. Phys. Lett. 70, 3209 (1997); S. Pezzagna, J. Brault, M. Leroux, J. Massies, M. de Micheli, J. Appl. Phys. 104, 106101 (2008). 